\title{
Use of Hybrid Phase Shifter for Congestion Management in A Grid with RESs and EVS: Transmission Efficiency Benefit in Comparison with
Use of Phase Shifting Transformer
}

\author{
Salah Eldeen Gasim Mohamed Hassan \\ Department of Electrical Engineering, College of Engineering \\ Sudan University of Science and Technology \\ Khartoum, Sudan \\ Email: salagasim@yahoo.com
}

\begin{abstract}
Integration of renewable energy sources (RESs) and electric vehicles (EVs) to electric power grids is increasing. These RESs and EVs may introduce major problems to powers grids such as transmission lines congestion. Owing to the causative factors nature, congestion may regularly happen and continue for long commulative time. Thus, transmission efficiency (TE) is a major factor when relieving such congestion. Congestion can be relieved by using phase shifting transformers (PSTs), hybrid phase shifters (HPSs), or flexible AC transmission system (FACTS) devices. However, PSTs have technical drawbacks such as their large steps, which may result in increased losses, and FACTS devices cost is high. This paper investigates benefits of using an HPS rather than a PST in terms of TE. As HPS operates continuously, it provides more precise control of active power flow than PST. A modified IEEE-14 bus test system is used and a security margin is kept in each simulated case with HPS/PST. Results revealed higher TE when an HPS is used. Based on that, RESs and EVs can be more optimally hosted with HPSs.
\end{abstract}

Keywords - electric vehicles, grid flexibility, hybrid phase shifter, phase shifting transformer, renewable energy sources, transmission efficiency.

\section{INTRODUCTION}

Many factors are arising that necessitate rethinking on the way power grids are operated and controlled. Such example is the rapid increase in production of electrical energy from renewable energy sources (RESs) such as wind and solar [1]. Another example is the move to integrate electric vehicles (EVs) to power grids. Power grids of today combine RESs and EVs and these units' penetration level is increasing, and the trend is expected to continue in the near future. China has a road map that predicts having wind power capacity of $200 \mathrm{GW}$ by $2020,400 \mathrm{GW}$ by 2030 , and $1000 \mathrm{GW}$ by $2050[2,3]$. Also, report of the department of energy (DOE) of the US has examined the technical perceptibility of generating $10 \%$ of country's electric power demand in $2020,20 \%$ in 2030 , and $35 \%$ in 2050 [4, 5] from wind energy. On the other hand, there was an official goal in the US to put one million EVs on road by 2015 [6]. With recent gas prices averaging less than $\$ 2$ per gallon while was averaging nearly $\$ 4$ in 2008 , it will take up to 2020 to reach one million EVs on road [7, 8]. However, public policies to encourage vehicles electrification have been implemented by governments [6]. Future of EVs remains extremely bright, and the goals are to make EVs as affordable as gasolinepowered vehicles by 2022 [7]. In deregulation and smart grid era, RESs and EVs are expected to be widely used as they are environment-friendly energy sources/sinks those highly reduce environment pollution. RESs have far low running costs and feasibility of EVs is evident especially when their batteries are charged at times of light load, or even better when charged from RESs. Combination of RESs and EVs ensures an overall fruitful and optimized operation [9]. Besides, it is advantageous to utilize RESs and EVs output fully and commit them to the highest possible degree owing to their reduced operational costs [10].

\section{CHARACTERISTICS OF RESS AND EVS}

Wind speed is subject to seasonal and inter-annual variations. It may increase to high values, drop to low values, or even cease to almost zero. In a stormy weather, a wind farm (WF) may be completely shut down for safety purposes [12]. When storms cause damage of wind turbines, shutdown may last for long time. Considering two WFs, "A" with 60 wind turbines and "B" with 28 , Macdonald et al., [18] found out percentage of incidents of $50 \%$ and $100 \%$ loss of availability of WFs " $A$ " and " $B$ ", due to high wind speed shutdown (HWSS). They stated that, for WF "A", $15.8 \%$ of HWSS incidents for the period $10^{\text {th }}$ January 2010 $12^{\text {th }}$ August 2013, approximately resulted in loss of at least $50 \%$ turbine availability.

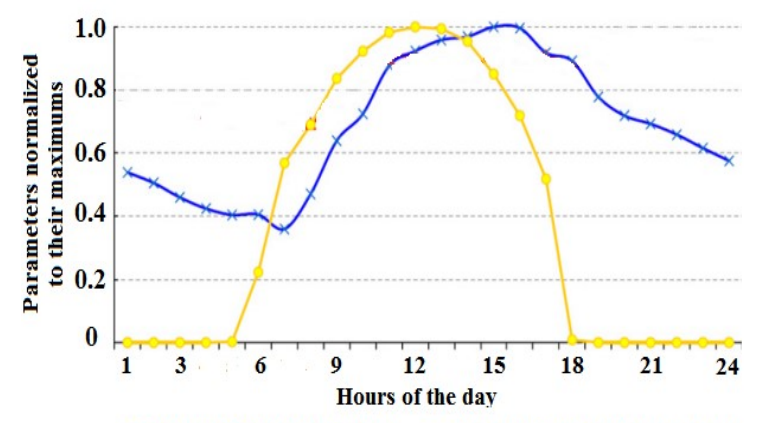

$\rightarrow$ Wind Speed (December) $\rightarrow$ Solar Radiation (December)

Fig. 1 Hourly variation of the parameters 
normalized to their maximum value in summer [13]

Also, they found that $6.7 \%$ of HWSS incidents resulted in complete loss of turbine availability and hence generation at site. Percentages for WF "B" are found to be $34.4 \%$ and $9.38 \%$ respectively. As a daily routine, WFs output may drop to about $50 \%$ for hours. On the other hand, output power of solar PV units depends on solar irradiance. In many countries, sun shines for about 12 hours and completely vanishes for the rest of time. Besides, fluctuation of solar irradiance during daytime due to clouds causes fluctuation of the output power. Fig. 1 shows daily curves of wind speed, and solar radiation in summer [13]. Output power of wind and solar farms fluctuates accordingly [11].

EVs have different operation modes. They are discontinuous energy sources and varying loads. During a day, they are whether connected to charge their batteries $(\mathrm{G} 2 \mathrm{~V})$, connected to discharge (V2G), or are not connected to grid. When connecting EVs to charge, batteries may take considerable portion of time to fully charge [14]. Batteries charging time depends on charger power level, battery capacity, and vehicle technology. For level 1 (slow) charger, charging time ranges from 4 to 36 hours. For level 2 (semifast) charger, charging time ranges from 1 to 6 hours. Finally, for Level 3 (fast) charger, charging time ranges from 0.2 to 1 hour [14]. However, according to Electric Power Research Institute (EPRI) [15], most EVs owners are likely to charge overnight at home. Hence, Level 1 and Level 2 charging are most used [16]. It is also stated by [17] that charging EVs with level 1 charger (standard $120 \mathrm{~V}$ outlets at home) is enough for most drivers, and availability of $120 \mathrm{~V}$ outlets in many locations is more beneficial than availability of fast chargers in fewer locations.

\section{Problem Statement}

Transmission lines are subjected to congestion in consequence of WFs and PV stations generation increase, as well as in consequence of EVs charging. Wu [21] has checked effect of EVs integration to power distribution networks and found a notable effect up to voltage levels of $60 \mathrm{kV}$. Similarly, in other studies [22], [23], it is found that congestion, which is caused by EVs, is apparent at mediumvoltage level. At their high penetration level, operation pattern of RESs and EVs is likely to severely alter generation and load shape, and thus transmission lines flows, causing their congestion [19]. This is because distribution and transmission systems are not initially designed to house such additional generation and load [20], with its obvious dynamics. Also, non-exact forecast of wind energy production several hours ahead affects scheduling of power systems and thus deteriorates lines loading security. Congestion, which is caused by RESs and EVs dynamics, may routinely take place, and each time it happens, it may last for long time. As the causative factors occur repeatedly and may last for long periods, significant problem when relieving transmission line congestion, which is caused by RESs and EVs dynamics, is deterioration of transmission efficiency (TE). While congestion of transmission lines can be relieved by shifting excess power to other transmission lines, precise shift while observing line loading is important. This is mainly due to that, power shift to other lines may decrease transmission efficiency. Use of step-wise control based PFCs such as PSTs may not result in best possible TE.

\section{Mitigation TeChNiQues of INTERMitTEnCyOF RESS AND VARYING CHARGING/LOAD OF EVS}

These include techniques that are performed to mitigate

violations created by intermittency of RESs and varying charging and discharging of EVs. Some main techniques to mitigate intermittency of RESs include aggregation of WFs, use of energy storage systems (ESSs), and enhancement of grid flexibility. Aggregation of WFs stabilizes their overall output power [10]. Fig. 2 shows the normalized output power of five equally rated WFs located in the N. Ireland area with the resulting output of all of WFs.

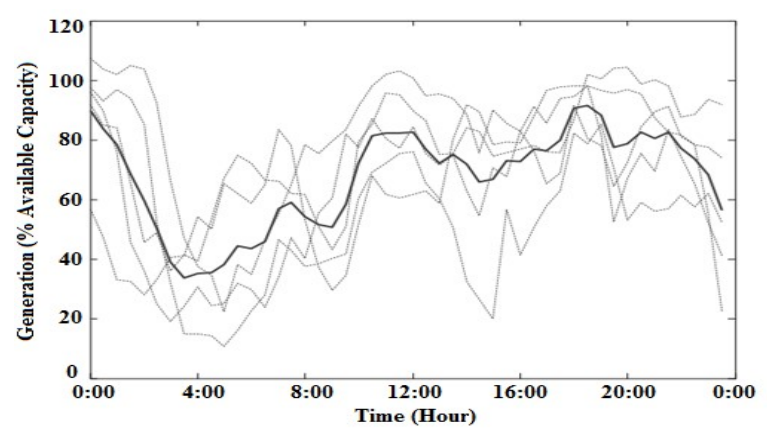

Fig.2 Five WFs variability (24 Hours) [10]

In Fig. 2, resulting output in a darker line, although has fewer fluctuations, final degree of fluctuation is still high. Also, suitable level of aggregation that diminishes fluctuations is not always practical. Besides, there are instants in which wind does not blow and thus, power drops to zero. Use of ESSs is beneficial to contain RESs intermittency. However, currently, they are not cost effective [25].

There are some solution classes to accommodate charging of EVs batteries without causing mentioned violations. The first class is advancement of grid infrastructure and the second is arrangement of distributed generation (DG) to cover the excess power demand [27]. The third is coordinating EVs charging by shifting it to optimal periods during the day through use of two-way communication facility of smart grid [27]. The third solution is more beneficial for both EVs owners and power utilities [28]. A fourth solution to charge EVs batteries without violating lines flow limit, which is addressed in this paper, is redirecting line flows through network controls. While the first class of solution may not be cost effective and the second and third are may be more suitable with distribution networks, the fourth class proposed in this paper, is more effective to relieve transmission networks' congestion.

In conclusion, increased flexibility of transmission network enables counteracting dynamic changes caused by RESs and EVs intermittency. Consequently, inherent flexibility of power system is a crucial feature to manage 
congestion and accordingly optimally host large amounts of wind and PV power and integrate huge fleets of EVs safely. Use of competent PFCs for such purpose is promissing. Possible PFCs include phase shifting transformer (PST), hybrid phase shifter (HPS), and series flexible AC transmission systems (FACTS) devices such as TCSC, SSSC, and UPFC. These FACTS devices can alleviate overloads of lines and counteract changes in grid operation quickly and smoothly. However, their high cost restricts their wide use. The PST is a simple and efficient PFC. It can successfully relieve lines congestion. Also, response time of PST is in seconds while allowed emergency congestion time is in minutes [29]. However, PST has some technical limitations such as its large steps size. These steps size may not always result in optimal operation of grid in terms of power loss. The smooth phase shifter HPS [30] has many advantageous features. These include precise and optimized control action and increased flexibility. They also include aiding operation of power systems closer to their security and stability limits as the HPS response is faster than the PST. While both PST and HPS can relieve congestion, the later is expected to be superior. Accordingly, use of HPS is expected to guarantee attaining more optimized results.

Relieving congestion of a congested line through use of network controls is highly beneficial. As compared to use of series FACTS devices to alleviate congestion, it is cost effective to use PSTs [24], or HPSs. As preceded in above sections, congestion that is caused by RESs and EVs dynamics may last for considerable period of time and/or may frequently occur. Optimal operation in terms of TE when relieving congestion caused by RESs and EVs dynamics may not take place unless a precise control action is performed. Thus, it is essential to assure that the strategy, which is used to relieve lines congestion, results in highest possible TE. This paper examines the power TE benefit of using a smooth phase shifter (HPS) as compared to use of conventional PST. This is due to that, while PSTs operate disecretly, HPSs operate continuously. Accordingly, when shifting lines flows, HPSs enable performing more precise adjustment. This paper mainly investigates efficiency benefit of using an HPS as a continuously acting PFC, rather than using a PST.

\section{Methodology of StUdy}

Present paper investigates and compares TE when using PSTs and HPSs to relieve congestion. Lines flow security is checked using a performance index. MATLAB/SIMULINK is used to model the system and perform the study. First, load flow analysis is simulated to investigate effects of the three considered operating conditions on the lines flow security and the TE. Then a PST and an HPS is used interchangeably to relieve the congestions. The flow security of three main paths is observed during occurrence of these operating conditions and when a PST or an HPS is used to alleviate the overloads. Then, the TE is investigated when using the PST and HPS interchangeably.

\section{TRAnsmission Line LoAding PERformance IndeX}

State of the lines active power flow security can be tested through use of the $\left(P I_{P}\right)$ performance index [10]:

$$
P I_{P}=\sum_{\mathrm{i}=1}^{\natural}\left(\frac{p_{i}}{p_{i-\max }}\right)^{2 \mathrm{~K}}
$$

where $t$ is line number, $l$ is total number of lines, $P_{\mathbb{i}}$ is real power flow in line $(i), P_{i-\max }$ is real power loading limits of line $i$, and exponent $n$ is a positive integer.

Value of the positive integer $n$ is increased to vanish the masking error. Value of the performance index $P_{p}$ with high values of exponent $n$ is a large number for the operating conditions where a line is congested.

\section{CASE STUdy AND SimUlated SCENARIOS}

A modified IEEE-14 bus system, which incorporates a WF, a PV plant, and a group of EVs fleet, is shown in Fig. 3. Three scenarios (operating conditions) are simulated, which are: A. Connection of EVs fleet to charge, B. Shutdown of WF, and C. Trip of PV unit (or unplug of V2G-EVs). In primary operating condition, WF and the PV unit (or the V2G-EVs at bus 2) are connected. In this study, generated power at WF, PV plant, and V2G-EV injection buses is modeled as a constant active power with reactive power having an upper and lower limit, and the injection buses are modeled as voltage controlled buses. Additionally, PST and HPS have the same model in MATLAB/SIMULINK except that PST operates discretely, while HPS operates continuously. For uniformity, in this work, similar to PST, HPS is set to respond in 2 seconds.

\section{ASSUMBTIONS CONSIDERED}

For purpose of this study, considering one day basis (24 hours), PV units ${ }^{7}$ output is assumed equal to $90 \%$ of the plants ${ }^{3}$ rated capacity for 12 hours and zero for remaining 12 hours. WFs are assumed to produce $50 \%$ of their capacity for 8 hours, $100 \%$ for 8 hours, and zero for 8 hours. EVs are dealt with as a lumped one bulky load or source and are connected to charge for 8 hours, connected to discharge for 8 hours and disconnected for 8 hours. Also, the study focused on steady state load flow analysis ignoring the transition between the different operating conditions. This is logic as the study focuses on power loss which is affected by the durable operation modes. Considering the 24 hours basis, it is intended to investigate the efficiency benefit of using HPSs rather than using PSs to alleviate the congestions caused due to changing operation modes of RESs and EVs.

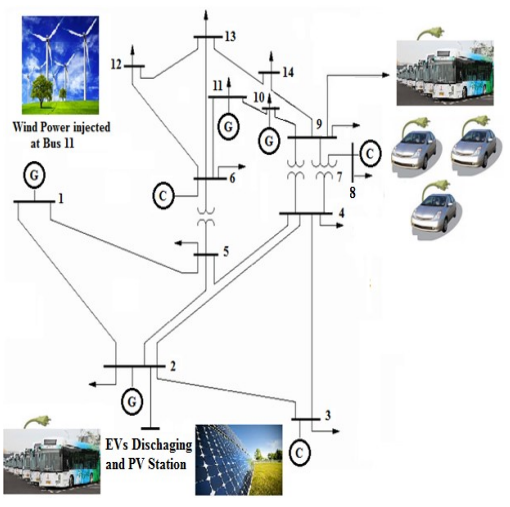

Fig. 3 A modified IEEE-14 bus system with RESs and EVs 
JAREE-Journal on Advance Research in Electrical Engineering Volume4, Number 1, April 2020

\section{Simulation Results AND Discussion}

Figs 4, 5, and 6 show active power flow in transformer (5-6) in base case and in each of considered three scienarios pre, and post PST/HPS action. Fig. 7 shows values of $P I_{P}$ without control, and with PST/HPS action interchangeably for considered three scienarios. From Figs 4, 5 and 6, it is evident that large steps of the PST (each step $=2.5 \mathrm{kV}$ ) cause a large jump in active power flow. In base case, active power flow in line 5-6, is within the prescribed limits. It is obvious that each of scenarios - charging of EVs fleet, shutdown of WF, and Trip of the PV (or unplug of V2G-EV at bus 2) - caused violation of flow limit of line 5-6. Violation relieve in all three scenarios is performed successfully with a PST and an HPS interchangeably. However, for first and third scenarios, with first step action, step-wise operation of PST resulted in reduction of line 5-7 active power flow to below its base case value. Jump of PST to first step resulted in increased power loss. Conversely, continuous action of HPS resulted in reduction of line 5-7 active power flow to close toits base case value. Accordingly, action of HPS resulted in fewer power loss. In the second scenario, shutdown of WF nessecitated two steps action of PST to releive congestion. First step did not relieve congestion. Nontheless, second step although releived congestion, resulted in increased power loss. Action of HPS resulted in fewer power loss with security margin maintained

\section{A. Charging of EVs fleet}

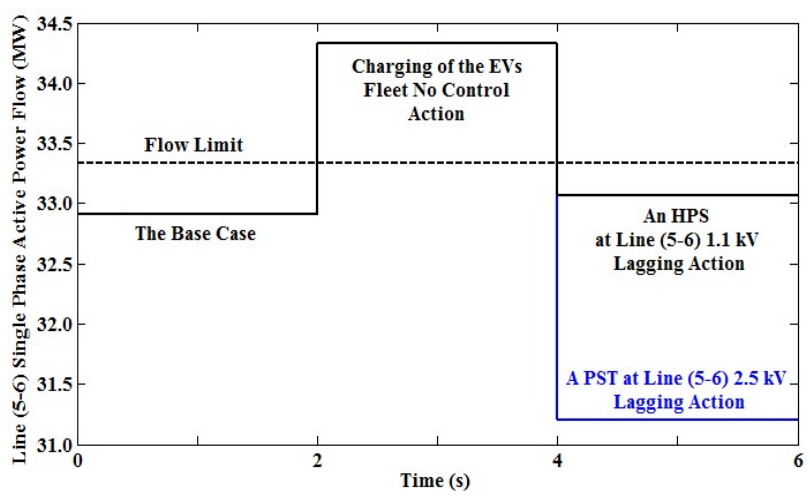

\section{B. Fig. 4 Charging of EVs fleet: Line (5-6) flow adjusting}

\section{Shutdown of $W F$}

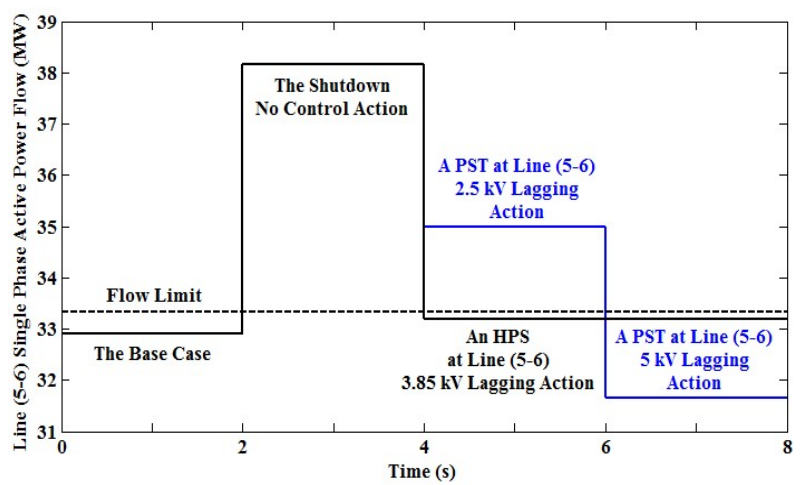

Fig. 5 Shutdown of WF: Line (5-6) flow adjusting
D. Trip of PV unit (or unplug of V2G-EVs)

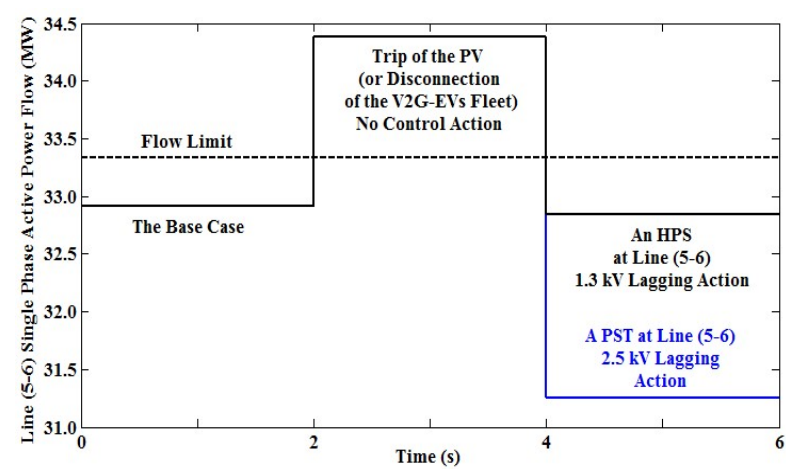

Fig. 6 Trip of the PV (or unplug of V2G-EV at bus 2): Line (5-6) flow adjusting

Transition of HPS is precise and thus enables a smooth and accurate control of active power. With an HPS, it is obvious that a line flow can be maintained closer to the limits with the essential security margin kept. When operating close to the limits, the fast response of HPS ensures maintaining grid operating safely and stably in case of occurrence of any disturbance. In Fig.7, it is obvious that paths flow is secured with PST/HPS.

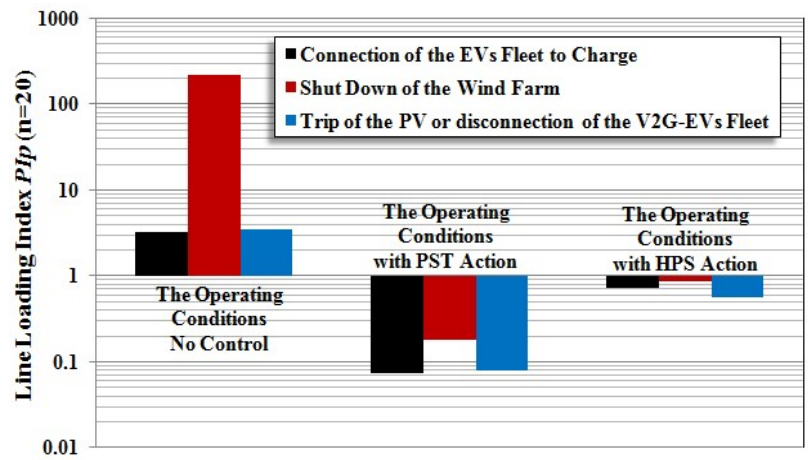

Fig. 7 PIp index for the considered three scenarios without control, with PST action, and with an HPS action

Fig. 8 shows TE in each of three different operating conditions when using a PST/HPS interchangeably. It is obvious that TE is higher in each of three considered operating conditions when an HPS is used as compared to TE when a conventional PST is used.

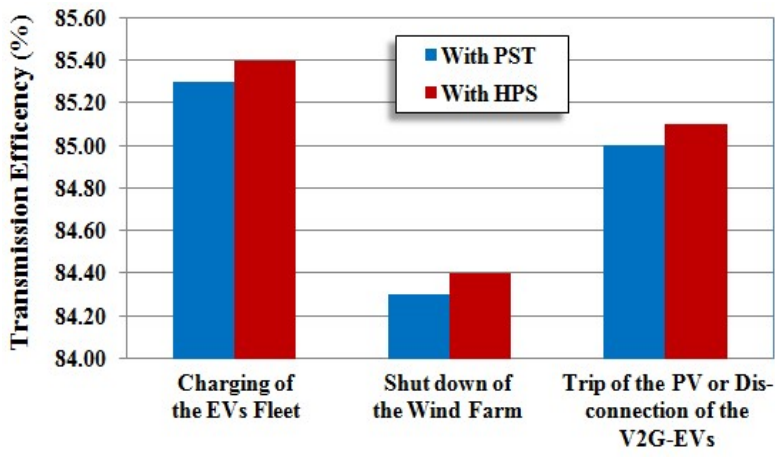

Fig. 8 TE when using a PST and when using an HPS for the considered three scenarios 
It is seen that. when it results in a higher efficency, HPSs enable passing as much as possible power - within limits - in a transmission line. On the other hand, when it results in a lower efficency, HPSs enable passing as less as possible power in a transmission line with all lines limits satisfied.

\section{CONClusion}

RESs intermittency as well as EVs connection and disconnection may cause transmission lines congestion. It is possible to relieve congestion by using a PST, a series FACTS device, or an HPS. Since operation conditions that are caused by RESs and EVs operation modes happen regularly and take a considerable overall duration,TE during these situations is of paramount importance. This paper has addressed comparison of power transmission efficiency (TE) when using a PST and an HPS interchangeably to relieve congestion caused by RESs and EVs dynamics. Three operation scenarios with congestion, which are caused by EVs charging, WF shutdown, and PV trip (or V2G-EV unplug) are considered. The precise action of HPS as compared to that of the PST is advantageous. While both PST and HPS can relieve transmission grid congestions, due to its precise action, HPS always attains a higher TE.

\section{Appendix A. Data of Modified IeEe-14 Bus System}

Transmission lines and transformers impedance data are not altered. They are typical as those in [31]. Transformers active power capacity is taken as $100 \mathrm{MW}$, and load and synchronous condensers ratings are altered to values that are given in TABLE I. TABLE I also includes amount of EVs load. TABLE II shows data of original and modified generating stations. These data represent type and capacity of the different generating stations and storages, which are namely, fossil, PV, wind, and EVs fleets.

TABLE A-1. MODIFIED LOAD AND COMPENSATION

$\begin{array}{ccccc}\begin{array}{c}\text { Bus } \\ \text { No. }\end{array} & \begin{array}{c}\text { P } \\ \text { (MW) }\end{array} & \begin{array}{c}\text { Q } \\ \text { (MVAr) }\end{array} & \begin{array}{c}\text { Synch. Cond. (Mvar) } \\ \text { Min }\end{array} & \begin{array}{c}\text { Max } \\ 3\end{array} \\ 80 & 20 & -20 & 40 \\ 4 & 70 & 30 & -30 & 120 \\ 5 & 90 & 40 & -30 & 130 \\ 6 & 48 & 20 & -20 & 20 \\ 8 & 60 & 20 & -20 & 20 \\ 9 & 65+20(E V s) & 34+1(E V s) & -- & -- \\ 11 & 60 & 30 & -- & -- \\ 12 & 40 & 30 & -- & -- \\ 14 & 120 & 50 & -50 & 90 \\ \text { Total } & 620 & 270 & -170 & 420\end{array}$

TABle A-2. Modified Generation And EVs FleEts Rated CAPACity

Generator No.
1
2
10
11
13

Type
Fossil
Fossil + PV/EVs
Fossil
Wind
Fossil

Rated Capacity (MW)
600
$60+20$
100
30
50

\section{REFERENCES}

[1] B. K.Sahu, M. Hiloidhari, and D. C. Baruah, "Global trend in wind power with special focus on the top five wind power producing countries," Renewable and Sustainable Energy Reviews, vol. 19, pp. 348-359, 2013.
[2] J. Kejun, H. Xiulian, Z. Xing, and L. Qiang,"China's Low-carbon Scenarios and Roadmap for 2050[J]," Sino-Global Energy,vol. 6, no. 6, pp. 21-26, 2009.

[3] Technology Roadmap, China Wind Energy Development Roadmap 2050, International Energy Agency (IEA), [Online]. Available: https://www.iea.org/publications/freepublications/publication/china_wind.pdf

[4] 20\% Wind Energy by 2030, Increasing Wind Energy's Contribution to US Electricity Supply, Tech. Rep. DOE/GO-102008-2567, July 2008, [Online]. Available: http://energy. gov/sites/prod/files/2013/12/ f5/41869.pdf

[5] 20\% Wind Energy by 2030, Increasing Wind Energy's Contribution to US Electricity Supply, [Online]. Available: http://energy.gov/ eere/wind/20-wind-energy-2030-increasing-wind-energys-contribution-uselectricity-supply

[6] A. Y. Saber and G. K. Venayagamoorthy, "One million plug-in electric vehicles on the road by 2015," in Proc. IEEE Intell. Trans. Syst. Conf., Oct. 2009, pp. 141-147.

[7] https://www.reuters.com/article/us-autos-electric-moniz/u -s-ma y-not-hit-onemillion-electric-vehicles-until-2020-offici al-idUSKC- NOUZ2MK

[8] http://www.sciencetimes.com/articles/8255/20160122/1m $\quad$-electr $\quad$-ic-carstarget-moved-2020.htm

[9] P. Lombardi, M. Heuer, and Z. Styczynski, "Battery switch station as storage system in an autonomous power system: optimization issue," in Power and Energy Society General Meeting, pp. 1-6, 2010.

[10] B. Fox, D. Flynn and L. Bryans, Wind Power Integration: Connection and system operational aspects, 2nd Edition, IET, 2014.

[11] H. Daneshi and A. K. Srivastava, "Impact of battery energy storage on power system with high wind penetration," In Proc. 2012 Transmission and Distribution Conference and Exposition, pp. 1-8.

[12] National Grid, High wind speed shutdown workgroup report, July 2013.

[13] P. De Jong, A. S. Sánchez, K. Esquerre, R. A. Kalid, and E. A. Torres, "Solar and wind energy production in relation to the electricity load curve and hydroelectricity in the northeast region of Brazil," Renewable and Sustainable Energy Reviews, vol. 23, pp. 526-535, 2013.

[14] M. Yilmaz, M., and P. T. Krein, "Review of battery charger topologies, charging power levels, and infrastructure for plug-in electric and hybrid vehicles," Power Electronics, IEEE Transactions on, 28(5), 2151-2169, 2013.

[15] M. Duvall, "Charging infrastructure update," in Proc. Electric Power Res. Inst. (EPRI), CPUC Electric Veh. Workshop, Mar. 2010.

[16] C. Botsford and A. Szczepanek, "Fast charging vs. slow charging: Pros and cons for the new age of electric vehicles," presented at the 24th Electric Vehicle Symposium, Stavanger, Norway, May 2009.

[17] S. Saxena, MD. Jason, and M. Scott, "Charging ahead on the transition to electric vehicles with standard $120 \mathrm{~V}$ wall outlets,: Applied energy 157, pp. 720-728, 2015.

[18] Macdonald, H., Hawker, G., and K. Bell, "Analysis of wide-area availability of wind generators during storm events," In Probabilistic Methods Applied to Power Systems (PMAPS), 2014 International Conference on, pp. 1-6. IEEE.

[19] R. Liu, L. Dow , E. Liu, "A survey of PEV impacts on electric utilities," In: Innovative smart grid technologies (ISGT), 2011 IEEE PES; 2011. pp. 1 - 8.

[20] M. F. Shaaban, A. A. Eajal, and E. F. El-Saadany, "Coordinated charging of plug-in hybrid electric vehicles in smart hybrid AC/DC distribution systems," Renewable Energy, pp. 82, 92-99, 2015.

[21] Q. Wu. Grid Integration of Electric Vehicles in Open Electricity Markets. John Wiley \& Sons, 2013.

[22] J.A.P. Lopes, F. J. Soares, and P.M.R. Almedia, "Identifying management procedures to deal with connection of electric vehicles in the grid," in Proc.2009 IEEE Bucharest PowerTech, pp. 1-8.

[23] K. Clement, E. Haesen and J. Driesen, "Coordinated charging of multiple plug-in hybrid electric vehicles in residential distribution grids, in Proc. 2009 IEEE/PES Power Systems Conference and Exposition, pp. 1-7

[24] S. Gasim Mohamed, J. Jasni, M. A. M. Radzi, and H. Hizam, "Enhancement of Environment-Friendly Power Grids Flexibility to Successfully Host RESs and EVs," Joint International Conference on Electrical, Control, and Computer Engineering 2015, (InECCE 2015), 27-28 October, Universiti Malaysia Pahang, Pekan, Pahang, Malaysia.

[25] M. M. Begovic (Ed.), Electrical Transmission Systems, and Smart Grids: Selected Entries from the Encyclopedia of Sustainability Science and Technology. Springer Science \& Business Media, 2012. 
JAREE-Journal on Advance Research in Electrical Engineering

Volume4, Number 1, April 2020

[26] MF. Shaaban, YM. Atwa, FF. El-Saadany "PEVs modeling and impacts mitigation in distribution networks," IEEE Trans Power Syst, 2013; 28(2):1122e31.

[27] H. Khayyam, H. Ranjbarzadeh, V. Marano "Intelligent control of vehicle to grid power," J Power Sources 2012; 201:1e9.

[28] RA. Verzijlbergh, MO. Grond, Z. Lukszo, JG. Slootweg, MD. Ilic "Network impacts and cost savings of controlled EV charging" IEEE Trans Smart Grid 2012; 3: 1203e12
[29] Capacity Rating Procedures by the System Design Task Force, August 1970, Corrected October 2004 [Online] Available: www.isone.com/rules_proceds/isone.../capacity_rating_proced -ures.pdf

[30] B. K. Johnson, and G. Venkataramanan, "A hybrid solid state phase shifter using PWM AC converters," IEEE Trans. Power Delivery, vol. 13, no.4, pp. 1316-1321, 1998.

[31] Power Systems Test Case Archive - UWEE, University of Washington [Online]. Available:www.ee.washington.edu/ research/pstca/ 